\title{
Role of cervical length evaluation with transvaginal ultrasound for prediction of preterm delivery in low risk pregnancy
}

\author{
Sirupa Venkata Geetika Reddy*, S. R. Mudanur
}

Department of Obstetrics and Gynecology, Shri B M Patil Medical College, Vijayapur, Karnataka, India

Received: 26 March 2018

Accepted: 01 May 2018

\section{*Correspondence:}

Dr. Sirupa Venkata Geetika Reddy,

E-mail: geethikareddy166@gmail.com

Copyright: (c) the author(s), publisher and licensee Medip Academy. This is an open-access article distributed under the terms of the Creative Commons Attribution Non-Commercial License, which permits unrestricted non-commercial use, distribution, and reproduction in any medium, provided the original work is properly cited.

\begin{abstract}
Background: Preterm birth possess a major health burden to the society due to its long - term morbidity, perinatal mortality and high financial expenditures associated with it. Transvaginal ultrasonographic measurement is an effective and objective way of measuring the cervical length. Cervical length $<25 \mathrm{~mm}$ is considered as the best cervical parameter with a good predictive accuracy for preterm birth. This study was taken up to study the role of cervical length measurement in predicting preterm labor by Trans vaginal sonography (TVS) and to measure cervical length and follow up cases to study the fetal outcome.

Methods: Sagital long-axis view of endocervical canal along the entire length was obtained with high frequency endovaginal probe and the length of cervix from external to the internal os was measured. Atleast three measurements were obtained and the best shortest measurement in millimeters was recorded. Transfundal pressure was applied for 15 seconds and cervical length was obtained again. The cases are followed till delivery and outcome is noted.

Results: Out of 134 study group of low risk women, 5.9\% women and 50\% of the women with short cervical length $(<25 \mathrm{~mm})$ had preterm birth. The sensitivity, specificity, positive predictive value, negative predictive value and accuracy of our study are $75 \%, 95.2 \%, 50 \%, 98.4 \%, 94 \%$ respectively. Among the 134 newborns, majority of the admissions (14) were due to birth asphyxia followed by meconium aspiration syndrome.

Conclusions: TVS is a useful technique in assessing the cervical changes during pregnancy and predicting the preterm birth especially when performed between 16-24 weeks of gestational age could identify all the women having short cervical length along with other changes of cervix.
\end{abstract}

Keywords: Cervical length, Preterm birth, Transvaginal sonography

\section{INTRODUCTION}

The average duration of normal human pregnancy is 267 days after conception or 280 days or 40 weeks calculated from the first day of last normal menstrual period. Preterm birth is defined by WHO as the one that occurs after 20 weeks of gestation and before completion of 37 menstrual weeks of gestation regardless of birth weight (BW). ${ }^{1}$ Preterm birth (PTB) is estimated to affect approximately 13 million births worldwide as per the censes of year- 2005 which accounts to $9.6 \%$ of all births. Africa and Asia accounted for almost 11 million preterm births. ${ }^{2}$ Higher preterm birth rates are recorded in Africa $(11.9 \%)$ and North America $(10.6 \%)$ and lower rates in Europe $(6.2 \%){ }^{1}$ According to the reviewed version of WHO - November 2016, each year, 15 million babies are born preterm. This accounts to more than 1 in 10 babies. Among children of age less than 5 years, prematurity is considered as the prime cause of death. ${ }^{3}$ When compared with other causes, preterm birth accounts for large number of complications related to newborn and infant death. India is one among the top 10 countries with the greatest number of preterm births - 35,19,100 preterm births every year. ${ }^{4}$ 
Preterm labour is defined by WHO as the onset of labour before 37 completed weeks of gestation (or) 259 days of pregnancy. The lower limit of the gestational age varies from 20 - 28 weeks. $^{5}$ Every year, nearly 1 million children die with the complications of preterm birth (2013). Across 184 countries, preterm birth rate is in between $5 \%$ to $18 \%$ of new born babies. In India, every year 27 million babies are born (2010 data), among them 3.5 million babies are born premature. ${ }^{6}$

Based on the gestational age preterm birth is inturn divided as early preterm whem women deliver before 33 weeks 6 days and late preterm when they deliver between 34 and 36 of completed gestational weeks.

Risk Factors for preterm labor are prior preterm birth, prior conization, polyhydramnios, short cervix, placental abruption, placenta previa and uterine malformations. Various tests performed for diagnosing preterm labor include sterile speculum examination to assess the $\mathrm{pH}$ of the cervical secretions, fern pattern and to obtain fibronectin swabs and cervical and vaginal cultures, digital examination of cervix to assess the effacement and dilatation of cervix, transabdominal ultrasound and transvaginal ultrasound examination of cervix.

\section{METHODS}

134 pregnant women with singleton pregnancy who attended outpatient department or admitted for antenatal care in the Departmetn of Obstetrics and gynaecology of BLDE University's Shri B. M. Patil Medical College, Hospital \& Research Centre, Vijayapura between December 2015 to June 2017 (18 months) were included in the study. The inclusion criteria followed were singleton pregnancy, gestational age between 16 and 24 weeks, informed consent to participate in the study and to undergo TVS. The exclusion criteria followed were severe anemia, multiple pregnancy, heart diseases, previous history of surgery on cervix (cervical dilatation, conisation), prior preterm birth and polyhydramnios.

The women selected for the study were counseled and informed written consent for the procedure was obtained after explaining the procedure in detail. Detailed history of the patient was taken. After the women emptied the bladder, a clean probe covered with a condom was inserted and guided into the anterior fornix of vagina and sagittal long-axis view of endocervical canal along the entire length was obtained. Transvaginal ultrasound scanning was done with high frequency endovaginal probe (5-7 Mhz). The probe was withdrawn until the image was blurred and just enough pressure was reapplied to restore the image so that excessive pressure on the cervix, which can elongate it, can be avoided. The image was then enlarged so that cervix occupied at least two-thirds of the image and both the external and internal os were seen. The length of cervix from external to the internal os was measured along the endocervical canal.
Three measurements were obtained and the best shortest measurement in millimeters was recorded.

Transfundal pressure was applied for 15 seconds and cervical length was obtained again. Cervical changes like funneling, funnel length, funnel width, cervical index, anterior cervical width, posterior cervical width were noted. All the pregnant women were followed up till their delivery and information regarding the delivery, baby and associated complications were noted.

\section{RESULTS}

One hundred and thirty four low risk women between 16 - 24 weeks of gestation who fulfilled the selection criteria were recruited for the study. Maximum number of cases were found in the age group of $20-25$ years $(45.5 \%)$, followed by women between 18- 20 years. Very few patients $(4.5 \%)$ were over 30 years of age (Table 1$)$.

Table 1: Distribution of cases according to age.

\begin{tabular}{|lll|}
\hline Age (yrs) & $\mathbf{N}$ & $\%$ \\
\hline $18-20$ & 43 & 32.1 \\
\hline $21-25$ & 61 & 45.5 \\
\hline $26-30$ & 24 & 17.9 \\
\hline$>30$ & 6 & 4.5 \\
\hline Total & 134 & 100 \\
\hline
\end{tabular}

Most of the patients in the study group were multi parous, accounting for $61.9 \%$. $51(38.1 \%)$ patients had only 1 child (Table 2).

Table 2: Distribution of cases according to parity.

\begin{tabular}{|lll|}
\hline Parity & N & $\%$ \\
\hline P1 & 51 & 38.1 \\
\hline P2 & 52 & 38.8 \\
\hline P3 & 25 & 18.7 \\
\hline P4 & 4 & 3 \\
\hline P5 & 2 & 1.5 \\
\hline Total & 134 & 100 \\
\hline
\end{tabular}

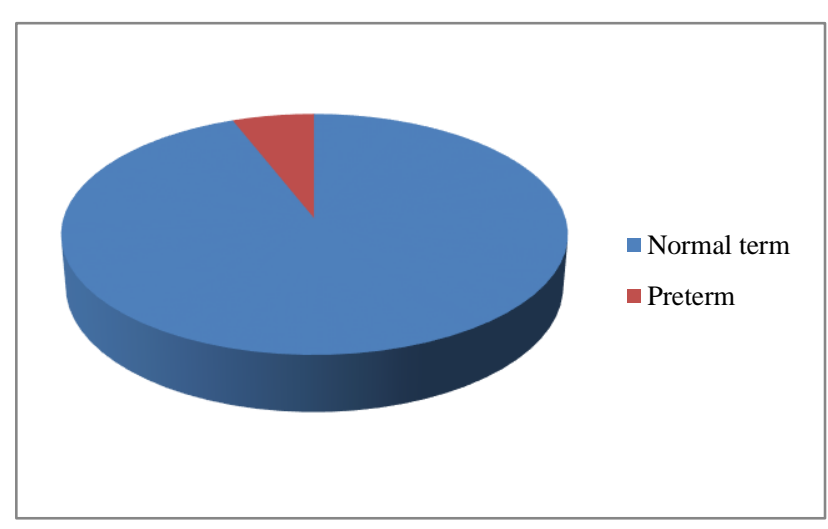

Figure 1: Incidence of preterm deliveries. 
Incidence of preterm deliveries were observed in 8 $(5.9 \%)$ of the cases (Figure 1).

In our study group of 134 women, 12 had cervical length less than $25 \mathrm{~mm}$ on transvaginal ultrasonography when measured between 16 - 24 weeks of gestation. Out of them, 6 women had preterm birth before 34 weeks of gestation $(50 \%)$. Among them, 5 women had funneling od the cervix done and all these 5 women had given preterm birth. Out of the rest of the women, 2 women who had $>25 \mathrm{~mm}$ cervical length had given birth prematurely (Table 3).

Table 3: Correlation between cervical length and preterm birth.

\begin{tabular}{|llll|}
\hline $\begin{array}{l}\text { Cervical } \\
\text { length }\end{array}$ & & Funneling & Preterm \\
\hline$<25 \mathrm{~mm}$ & 12 & 5 & 6 \\
\hline$>25 \mathrm{~mm}$ & 122 & 0 & 2 \\
\hline Total & 134 & 5 & 8 \\
\hline
\end{tabular}

Maximum number (93) of newborns had birth weight in the range $2.5-3 \mathrm{~kg}$ and 18 newborns had birth weight $<2.5 \mathrm{~kg}$ (Table 4).

Table: 4. Distribution of cases according to birth weight.

\begin{tabular}{|lll|}
\hline Birth weight $(\mathrm{kg})$ & $\mathrm{N}$ & $\%$ \\
\hline$<2.5$ & 18 & 13.4 \\
\hline $2.5-3.0$ & 93 & 69.4 \\
\hline$>3$ & 23 & 17.2 \\
\hline Total & 134 & 100 \\
\hline
\end{tabular}

In our study, the cervical length of the women is statistically significant and has a negative correlation with the age of women $(r$ value $=-0.244 ; p$ value $=0.004)$ and her gestational age ( $r$ value $=-0.349$; $p$ value $=<0.001$ ). Birth weight has a positive and statistically significant correlation $(\mathrm{r}$ value $=0.296$; $\mathrm{p}$ value $=0.001)$ with cervical length (Table 5).

Table 5: Pearson correlation coefficient between cl and other parameters.

\begin{tabular}{|lll|}
\hline & r value & p value \\
\hline AGE $(\mathrm{kg})$ & -0.244 & $0.004^{*}$ \\
\hline BMI $\left(\mathrm{kg} / \mathrm{m}^{2}\right)$ & 0.029 & 0.741 \\
\hline GA $(\mathrm{Wks})$ & -0.349 & $<0.001^{*}$ \\
\hline Birth weight $(\mathrm{kg})$ & 0.296 & $0.001^{*}$ \\
\hline
\end{tabular}

Note: * significant at $5 \%$ level of significance $(\mathrm{p}<0.05)$

Using a cervical length threshold of $25 \mathrm{~mm}$ and spontaneous preterm birth before 37 weeks' of gestation as the reference standard the sensitivity, specificity, positive predictive value, negative predictive value and accuracy of our study are $75 \%, 95.2 \%, 50 \%, 98.4 \%, 94 \%$ respectively (Table 6).
Table 6: Sensitivity, Specificity, Positive Predictive value (PPV) and Negative Predictive Value (NPV) among the study group women.

\begin{tabular}{|ll|}
\hline & Cervical length $(\mathrm{mm})$ \\
\hline & $\leq 25$ \\
\hline Sensitivity & $75.0 \%$ \\
\hline Specificity & $95.2 \%$ \\
\hline PPV & $50.0 \%$ \\
\hline NPV & $98.4 \%$ \\
\hline Accuracy & $94.0 \%$ \\
\hline
\end{tabular}

\section{DISCUSSION}

Preterm birth possess a major health burden to the society due to its association with long - term morbidity, perinatal mortality and high financial expenditures. It is responsible for more than half of all neonatal deaths ${ }^{7}$. Moreover, of late, the incidence of preterm birth is on the rise in spite of the good perinatal care, which has been indirectly attributed to multiple pregnancy.

Transvaginal ultrasound (TVU) is a useful in diagnosing short cervix during pregnancy, which predicts preterm birth not only in high risk group but also in asymptomatic low-risk women.

In the present study, 12 pregnant women had cervical length less than $25 \mathrm{~mm}$ on transvaginal ultrasonography when measured between 16 - 24 weeks of gestation. Out of them, 6 women had preterm birth before 34 weeks of gestation (50\%). The sensitivity, specificity, PPV, NPV, recorded in our study are 75\%, 95.2\%, 50\%, 98.4\% respectively. The combined presence of a shorter cervical length and funneling was found to be a better predictor of preterm birth than short cervix alone.

Transvaginal ultrasound measurement of cervical length was found to be a superior method of measurement by Hernandez-Andrade et al and Friedman et al which corroborated our study. ${ }^{8,9}$ They had reiterated that cervical length could not be measured accurately by transabdominal ultrasound and transvaginal ultrasound measurement was a superior method.

In another study by Dennis et al on 2915 low risk pregnant women, the incidence of preterm birth was estimated to be $4.3 \%$ which was comparable to the incidence of $5.9 \%$ in the present study. The sensitivity, specificity, PPV, NPV in their study was $47 \%, 84 \%, 35 \%$ and $90 \%$ respectively in contrast to are $75 \%, 95.2 \%$, $50 \%, 98.4 \%$ respectively in the present study.

This was perhaps due to the assessment of the cervical length from 22 weeks period of gestation, and thus may have missed some shorter cervical lengths. Thus our study proves that transvaginal ultrasound aids in predicting PTB in low risk population. ${ }^{10}$ 
In yet another study by Barber et al, the specificity, sensitivity, positive and negative predictive values of cervical length for assessing preterm birth was reported as $98 \%, 26 \%, 63.6 \%, 93.57 \%$ respectively, which was slightly lower than that of our study. ${ }^{11}$

In a study by Lim et al transvaginal ultrasound for the measurement of cervical length was reported to be a very effective, safe and acceptable technique in predicting the preterm birth. Cervical length was reported to be inversely related to the risk of preterm birth in asymptomatic women. ${ }^{12}$

Dalali et al conducted a observational cohort study in a total of 450 women from 508 eligible participants between 21-24 weeks of gestation. 47 cases had preterm labor out of 450 cases and 6 cases had positive funneling. Duration of pregnancy and cervical length significantly differed between women with and without funneling $(p=0.001)$. The sensitivity and specificity of screening based on cervical length of $25 \mathrm{~mm}$ were $55.5 \%$ (50.9$60.1 \%)$ and $93.6 \%(91.2-96 \%)$ respectively.

\section{CONCLUSION}

Transvaginal sonography (TVS) is a useful technique in assessing the cervical changes during pregnancy and predicting the preterm birth. Transvaginal sonography when performed between 16 - 24 weeks of gestational age could identify all the women having short cervical length and also with other changes of cervix.

\section{Funding: No funding sources}

Conflict of interest: None declared

Ethical approval: The study was approved by the Institutional Ethics Committee

\section{REFERENCES}

1. Creasy RK, Resnik R. Creasy \& Resnik's MaternalFetal Medicine: Principle and Practice. Saunders Elsevier, Philadelphia; 2009.

2. Beck S, Wojdyla D, Say L, Betran AP, Merialdi M, Requejo $\mathrm{JH}$, et al. The world wide incidence of preterm birth: a systemic review of maternal mortality and morbidity. Bull World Health Organ. 2010;88(1):31-8.

3. WHO. Worldwide incidence of Pre term birth. Available at: http://www.who.int/mediacentre/ factsheets/fs363/en. Accessed on 21 November 2017.

4. Blencowe H, Cousens S, Oestergaard MZ, Chou D, Moller AB, Narwal R, et al. National, regional, and worldwide estimates of preterm birth rates in the year 2010 with time trends since 1990 for selected countries: a systematic analysis and implications. Lancet. 2012;379(9832):2162-72.

5. Berghella V, Odibo AO, To MS, Rust OA, Althuisius SM. Cerclage for short cervix on ultrasonography: Meta-analysis of trials using individual patient - level data. Obstet Gynecol. 2005,106:181-9.

6. NHP. Worldwide incidence of Pre term birth \& it's Complications. Available at: https://www.nhp.gov. in/disease/reproductive-system/femalegynaecological-diseases-/preterm-birth. Accessed 21 November 2017.

7. Martin JA. Births: Final Data for 2006. Natl Vital Stat Rep. 2009;57(7). Available from: https://www .cdc.gov/nchs/data/nvsr/nvsr57/nvsr57_07.pdf.

Accessed 21 November 2017.

8. Hernandez-Andrade E, Romero R, Ahn H, Hussein Y, Yeo L, Korzeniewski SJ, et al. Evaluation of uterine cervical length during pregnancyfails to identify a substantial number of women with a short cervix. J Matern Fetal Neonatal Med. 2012;25(9):1682-9.

9. Friedman AM, Srinivas SK, Parry S, Elovitz MA, Wang E, et al. Can transabdominal ultrasound be used as a screening test for short cervical length? Am J Obstet Gynecol. 2013;208(3):190.e1-7.

10. Dennis JG, Berghella V. Cervical length and prediction of preterm delivery. Obstet Gynecol. 2007;19:191-5.

11. Barber MA, Eguiluz I, Plasencia W, Medina M, Valle L, Garcia JA. Preterm delivery and ultrasound measurement of cervical length in Gran Canaria, Spain. Int J Obstet Gynecol. 2010;108(1):58-60.

12. Lim K, Butt K, Fredericton NB, Crane JM. Ultrasonographic Cervical Length Assessment in Predicting Preterm Birth in Singleton Pregnancies. J Obstet Gynaecol. 2011;33(5):486-99.

13. Airoldi J, Berghella V, Sehdev H, Ludmir J. Transvaginal ultrasound of the cervix to predict preterm birth in women with uterine anomalies. Obstet Gynecol. 2005 Sep;106(3):553-6.

Cite this article as: Reddy SVG, Mudanur SR. Role of cervical length evaluation with transvaginal ultrasound for prediction of preterm delivery in low risk pregnancy. Int J Reprod Contracept Obstet Gynecol 2018;7:2852-5. 